\title{
"The taste of others": divergences in tastes between professional experts and ordinary consumers of movies in France
}

\author{
Stéphane Debenedetti \\ Associate professor \\ Dauphine Recherches en Management (DRM, umr 7088) \\ Université Paris-Dauphine \\ Fabrice Larceneux \\ Researcher CNRS \\ Dauphine Recherches en Management (DRM, umr 7088) \\ Université Paris-Dauphine
}

\begin{abstract}
$\underline{\text { Abstract }}$
The omnipresence of professional experts in the debates and marketing strategies around movies raises the question of the proximity of their judgments with those of the "ordinary consumer". Two theoretical perspectives compete on this matter: divergence or convergence of tastes. Based on a sample of 622 popular films released between 2005 and 2009 in France, this research confirms the divergence of tastes: professional experts grant no special value to movies that ordinary consumers prefer. However, our results also suggest that publication on the Internet of "hybrid" tastes (those of web users and media critics) builds an artificial form of convergence which can be useful for the market's actors.
\end{abstract}

Keywords: taste, judgment, professional experts, ordinary consumers, web users, critics, convergence, divergence, movies 


\section{Stéphane Debenedetti}

Associate professor

Dauphine Recherches en Management (DRM, umr 7088)

Université Paris-Dauphine

75775 Paris cedex 16

Tel: +33 (0)144054430

Fax: +33(0)144054449

Email: stephane.debenedetti@dauphine.fr

Home address: 41 rue Delambre 75014 Paris

\section{Fabrice Larceneux}

\section{Researcher CNRS}

Dauphine Recherches en Management (DRM, umr 7088)

Université Paris-Dauphine

75775 Paris cedex 16

Tel: $+33(0) 144054450$

Fax: +33 (0)1 44054449

Email: fabrice.larceneux@dauphine.fr

Home address: 2 rue du Bourg l'Abbé 75003 Paris

The authors would like to sincerely thank Jean-Jacques Boutaud, Alain Debenedetti and the four anonymous reviewers for their constructive comments, which greatly contributed to improving this article. 


\section{INTRODUCTION}

The products of cultural industries (movies, books, CDs, video games) are experiential prototypes whose quality cannot easily be assessed by the consumer before the actual experience. On cultural markets, the adjustment of supply to demand is not dictated by price (which is often uniform for products in the same category), but by judgment, which reduces uncertainty as to the product's quality. Among the judgments available within the public sphere, those rendered by specialists have shaped the discourse around works for some time: literary prizes, such as the Prix Goncourt in France, labels, such as Selection FIP, awarded to new records by a well-known radio station, awards such as the Fauve d'Or, designating the best comic book during the Angoulême festival, etc. In the motion picture industry, critical judgments are rendered by a multitude of interdependent sources. These include professional critics, film festival and prize juries (Cannes, César, Louis Delluc...) or members of various institutions in the sector (such as the "Centre National de la Cinématographie" - CNC commission for the advance funding of productions). Far from being marginalized, judgments published by professional experts frequently appear in promotional materials for movies (posters, press releases, official websites, trailers, promotional leaflets handed out in theatres) and are highlighted on specialized websites (in France allocine.fr features reviews as well as nominations and awards). These judgments are also the object of ritualized awards ceremonies, with the most prestigious ones garnering considerable media attention (Cannes, Césars, Oscars) and, over the long-term, contributing to the legitimacy and "classic" status of a movie, ensuring its place in various institutions in the field (academic courses, encyclopedia, retrospectives, film libraries, etc.). 
The judgments of motion picture specialists have several functions. For the "ordinary consumer" (Holbrook, 1999), the public expression of a specialist's taste is a form of experiential information $^{1}$ which allows him/her to reduce the risks associated with his/her decision. The underlying hypothesis of this guidance function is a certain proximity of judgment between ordinary audiences and specialists, ensuring the utility and credibility of the latter in the eyes of the former. However, specialist judgments are much more than simple opinions used by spectators in search of information to facilitate the decision making process. Sociologists also point to the fundamental symbolic role of the specialist's consecration as a guarantee of "good taste" (Holbrook, 1999) or legitimate taste (Bourdieu, 1979) when it comes to culture. Referring to the specialist's taste allows the ordinary spectator to make a "quality" decision, informed by the expert's opinion, to ensure the legitimacy of his choice from the standpoint of social distinction or, a posteriori, to auto-assess his tastes compared to a scale of consecrated values. For public authorities acting in the movie sector, the opinion of specialists represents an indicator for the allocation of public funds to support the production and distribution of certain films, but also educational programs (in schools, for example).

The central question raised in this article concerns the proximity between the judgments expressed by specialists and those of ordinary moviegoers for which these films are produced: does public opinion converge with legitimate tastes? More specifically, do ordinary consumers display "good" or "bad" taste? The answer to this question is far from neutral. It has significant implications, both in terms of consumer behavior and cultural policy. Professionals in the sector have become used to instrumentalizing the opinions of specialists to promote movies. However, this strategy does not make sense unless there is a convergence of tastes between specialists and audiences. Parallel to these preoccupations, the question also

\footnotetext{
${ }^{1}$ Information is qualified as experiential when it concerns the subjective experience of consumption (whether for the ordinary consumer or the specialist).
} 
raises the issue of public policy regarding culture and educating audiences, of the legitimacy of instances that recognize "good taste" and therefore the relevance of policies to support works esteemed by specialists (the promotion of certain works and distribution channels, the composition of legitimizing bodies...).

The problem of convergence of tastes between specialists and ordinary spectators concerns a long tradition in research, dominated by two theoretical perspectives. The first, rooted in critical sociology, explains there is a divergence between specialist and consumer tastes due to the social construction of criteria for excellence that are inaccessible for the ordinary spectator. The second points to, on the contrary, a convergence of tastes, theorizing that the hierarchical distinctions between cultural works prized by experts and a popular culture open to all have been blurred. While several recent studies in the United States argue there is a convergence in tastes between specialists and consumers in the movie sector, we propose questioning the scope of these results and their generalization in other contexts for at least two reasons:

- First, in France, there is a stronger tradition than in the United States of motion pictures as an autonomous art form with its own legitimizing institutions like the CNC (Centre National de la Cinématographie) or the Cannes film festival. These highlight the artistic dimension of the film and argue in favor of other approaches than pure entertainment value. In doing so, these institutions clearly assert the existence of a legitimate taste, defined by recognized specialists.

- Secondly, by renewing the methodological perspective of recent American studies, the French context offers an opportunity to enrich and refine previous measures of taste (the opinions of media critics for specialists and those of web users for ordinary spectators) with new operationalizations, deemed in this case closer to the value 
judgments of specialists (the Art et Essai criterion for independent films) and the approval of ordinary spectators (theater exit polls).

After explaining and discussing, in sociology and marketing, the two competing theoretical perspectives of divergence and convergence of tastes, we will question their validity in a French context and specify the characteristics of 622 movies and the four measures of taste mobilized for this study. The results of our research suggest that there is a divergence of tastes between "authentic" specialists and ordinary consumers, but also the construction of hybrid tastes on the web (the tastes of web users and the media), which conveniently bridge the seemingly insurmountable gap between the erudite and the novice. The implications of these results, on a theoretical and methodological level and for players in the movie field, are explained. Finally, this article ends with a discussion of the study's limitations and proposals for future research on the question of consumer tastes regarding cultural and eventually other experiential products.

THE JUDGMENT OF SPECIALISTS AND ORDINARY CONSUMERS REGARDING MOTION PICTURES

Divergence or convergence: two theoretical perspectives

Divergence of tastes between specialists and ordinary consumers

The opposition, in terms of art, between the legitimate taste of the specialist for authentic works of art and the taste of the "masses", attracted by a certain facility, is a recurring theme in the humanities and social sciences. Plato, in The Republic, already explained that the 
influence of audience tastes on theatrical productions threatened to diminish their quality. The audience's "bad taste" can be the fruit of deliberate industrial and commercial strategies. This was the theory put forward by German philosophers of the Frankfurt School in the 1930s (Adorno, Horkheimer, Marcuse). Their criticism of a mass culture distributed by cultural industries denounces the standardized and predictable nature of the resulting works (compared to "authentic" works of art). Sold to a passive and pliable audience of "cultural dopes", these mass products "dumb down" the tastes of ordinary consumers (see Alexander, 2003; Esquenazi, 2009). The absence of taste among the public at large can also be understood as constructed by a dominant elite seeking to preserve its social position. Hence the institutionalization of a hierarchy between "high" culture and "popular culture", allowing the $18^{\text {th }}$ and $19^{\text {th }}$ century bourgeois elite to impose its normative standard of taste where "good taste" is contrasted with the trivial pursuits of the masses (Assouly, 2008; DiMaggio, 1982a, 1982b; Levine, 1988). Those who have the power to dictate "good taste" are recognized specialists in the field i.e. players with the most cultural capital in a specific area, often acting as "gatekeepers" within their sector (critics, academics, curators, editors, program directors, etc.) Specialists possess the symbolic power of consecrating and establishing the "canons" of legitimate artists and works, according to a socially constructed set of standards (Becker, 1982; Bauman, 2007; Regev, 1994; Wijnberg and Gemser, 2000). Since the end of the $19^{\text {th }}$ century, the criteria of excellence have been based, first, on the innovative or original nature of the work in terms of art history (Wijnberg and Gemser, 2000; Regev, 1994). Founded on the analysis of artistic forms, the specialist's judgment corresponds to the objectification of an aesthetic quality in order to distinguish it from pure sensoriality (Assouly, 2008; Heinich, 2007). This is therefore a value judgment which reflects, in Bourdieu's terms (1979), a "pure

\footnotetext{
2 "Cultural dopes" is a term attributed to Harold Garfinkel in reference to passive consumers of mass-produced cultural products who can easily be manipulated.

${ }^{3}$ A gatekeeper is an individual or institution that controls access to a cultural arena and/or promotes or inhibits the development, production or distribution of various works.
} 
taste". Only a minority of consumers belonging to the cultural elite possess the skills and knowledge required to appropriate the specialist's "good taste". The specialist's standards of excellence are not accessible for the mass of ordinary consumers, who have too little cultural capital. The latter can only express a "pleasure judgment", reflecting a "taste of the senses" or "popular taste" founded on an immediate emotional apprehension of the work and its explicit content (Bourdieu, 1979, 1992). Thus, in critical sociology, the divergence of tastes between specialists and ordinary consumers reflects a social construction through which the dominant players preserve their superior position by imposing standards of excellence that are inaccessible to the ordinary consumer, who does not have the necessary knowledge to appropriate them (Bourdieu, 1979). In keeping with the dual meaning of "divergence" (difference or disagreement, according to Merriam-Webster), the divide between the official taste of specialists and the popular taste of ordinary consumers can translate into two independent worlds of taste, revealing the incapacity of the general public to recognize and appreciate authentic works of art, or, more radically, an opposition to taste, according to a "logic of distinction" among the cultural elite".

Towards a convergence of tastes between specialists and ordinary consumers

Several recent studies refute the theory of a divergence in artistic tastes, pointing to the blurring of contemporary symbolic boundaries between legitimate and popular cultures. DiMaggio (1991), Gans (1999) or Peterson (2004) identify a set of societal changes during the course of the $20^{\text {th }}$ century, and more specifically since the 1960 s, that attest to the gradual erosion of a system that institutionalized the former boundaries between the highbrow and the lowbrow established in the $19^{\text {th }}$ century. Certain changes contribute to a convergence of

\footnotetext{
${ }^{4}$ Taste being always, according to Bourdieu, a distaste for the taste of others.
} 
assessment criteria between specialists and ordinary consumers (greater mobility of social elites, wider access to higher education, greater tolerance...). Others encourage the creation of hybrid works, borrowing from both legitimate and popular cultures (managerialization of the cultural field, aestheticization of popular culture, references to popular works in high art...). One of the noticeable consequences of this trend is the replacement of the "snob", with exclusive tastes and a strong need for social distinction, by the eclectic omnivore. According to the "cultural omnivorousness thesis", what distinguishes today's dominant groups in terms of cultural capital is not their "univore" taste for works consecrated by specialists, but their cultural eclecticism (Peterson, 2004; Peterson and Kern, 1996). Research by Lahire (2004) on "cultural dissonance", from a micro-sociological perspective, suggests that consumers of culture, whatever their socio-cultural characteristics, now claim to have "plural" tastes, combining very heterogeneous practices and artistic preferences in terms of legitimacy, capable of appreciating with the same enthusiasm art house and blockbuster movies, opera, rock and pop music, premium and standard cable television. Overall, these recent studies challenge the hypothesis of a divergence in tastes. Moreover, they can be situated, for the most part, within a post-modern ethos according to which former ranking systems are fading in favor of more tolerant and relativist aesthetics (Lyotard, 1979). The elitist and standardized tradition of taste is qualified as dogmatic and aristocratic. Its strict standards are only obstacles to pure freedom of enjoyment. Thus, it is both this blurring of established frontiers between legitimate and popular tastes and the abolition of the very idea of such a boundary that would eventually bridge the gap (i.e. convergence) between specialist and ordinary consumer tastes.

The convergence of American tastes in motion pictures 
Recent American research in consumer behavior tends to confirm the theoretical perspective of converging tastes in motion pictures. In his seminal article, Popular appeal versus expert judgment of motion pictures, published in 1999 in the Journal of Consumer Research, Holbrook is the first to examine the link between expert judgments (critical essayists) and the judgments of ordinary moviegoers (assessed via an HBO poll). His aim was to test the theory of diverging tastes in the case of movies, by studying both the determinants of taste for these two categories of individuals (the term "taste" is understood as "preference" by Holbrook) and the correlation between these two forms of judgment. Holbrook shows that while the judgments of specialists and ordinary consumers are based on different criteria, the correlation between the two tastes is still slightly positive $(\mathrm{r}=0.25)$. For the researcher, these results challenge the theories of divergent tastes, at least in the field of motion pictures. Reproducing his research on three occasions in studies with broader ambitions in the field of movies (Holbrook, 2005; Holbrook and Addis, 2007) and jazz (Holbrook, Lacher, LaTour, 2006), Holbrook again observes a positive and moderate correlation between the tastes of specialists and ordinary consumers (from 0.225 to 0.365 ), a phenomenon that he theorizes as the "little taste" of the general public.

More recently, research in the psychology of creativity by Jonathan Plucker, published in Psychology and Marketing, explores the same question: "do experts and novices evaluate movies the same way?" Going beyond Holbrook's concept of "little taste", Plucker concludes that ordinary consumers show rather good taste, underlining the fact that the judgments of specialists (reviews collected on websites such as Rotten Tomatoes or Metacritic) and novices (reviews posted by web users on the same sites or obtained by polling students) saturate the same axis of a factor analysis (explaining $81 \%$ of the variance). Correlations between these two types of assessment range from 0.22 to 0.80 , with most greater than 0.4 (Plucker, Holden 
and Neustadter, 2008; Plucker et al., 2009). Plucker et al. (2009) also demonstrate that the correlations between the judgments of ordinary moviegoers (students polled) and media specialists (critics) vary between 0.22 and 0.44 according to the level of spectator involvement. The more films the spectator has seen in the proposed list, the closer his judgment is to those of the critics.

These recent studies (summarized in Table 1) suggest a partial convergence (moderate to strong) between specialist (critics) and ordinary consumer tastes (television audiences, web users or students) in the field of motion pictures.

Table 1 - Summary of Holbrook and Plucker's research on the proximity of specialist and ordinary consumer tastes in motion pictures

\begin{tabular}{|l|l|l|l|}
\hline Reference & $\begin{array}{l}\text { Measurement of } \\
\text { specialist taste }\end{array}$ & $\begin{array}{l}\text { Measurement of } \\
\text { consumer taste }\end{array}$ & $\begin{array}{l}\text { Correlation between specialist /consumer } \\
\text { taste }\end{array}$ \\
\hline Holbrook (1999) & $\begin{array}{l}\text { Evaluations from 6 } \\
\text { motion picture } \\
\text { guides }\end{array}$ & $\begin{array}{l}\text { Customer satisfaction } \\
\text { survey conducted by } \\
\text { HBO }\end{array}$ & r=0.25 \\
\hline Holbrook (2005) & $\begin{array}{l}\text { Evaluations from 6 } \\
\text { motion picture } \\
\text { guides }\end{array}$ & $\begin{array}{l}\text { Number of web user } \\
\text { votes on Imdb* }\end{array}$ & $\mathrm{r}=0.23$ \\
\hline $\begin{array}{l}\text { Holbrook and } \\
\text { Addis (2007) }\end{array}$ & $\begin{array}{l}\text { Evaluations posted } \\
\text { by critics on } \\
\text { Rotten Tomatoes }\end{array}$ & $\begin{array}{l}\text { Number of web user } \\
\text { votes on Imdb }\end{array}$ & $\mathrm{r}=0.25$ (study 1) then r=0.26 (study 2) \\
\hline $\begin{array}{l}\text { Plucker, Holden } \\
\text { and Neustadter }\end{array}$ & $\begin{array}{l}\text { Evaluations posted } \\
\text { by critics on } \\
\text { Rotten Tomatoes, } \\
\text { Metacritic, } \\
\text { National society of } \\
\text { film critics }\end{array}$ & $\begin{array}{l}\text { Web user evaluations } \\
\text { Tomatoes and Box } \\
\text { Office Mojo }\end{array}$ & $\begin{array}{l}\text { From r=0.55 to r=0.85 (depending on the } \\
\text { website) }\end{array}$ \\
\hline $\begin{array}{l}\text { Plucker et al. } \\
\text { (2009) }\end{array}$ & $\begin{array}{l}\text { Evaluations posted } \\
\text { by critics on } \\
\text { Metacritic }\end{array}$ & $\begin{array}{l}\text { Survey with 169 } \\
\text { students }\end{array}$ & $\begin{array}{l}\mathrm{r}=0.43 \text { for the entire sample } \\
\mathrm{r}=0.22 \text { for the least involved novices } \\
\mathrm{r}=0.39 \text { for moderately involved novices } \\
\mathrm{r}=0.44 \text { for the most involved novices }\end{array}$ \\
\hline
\end{tabular}

*Imdb (Internet movie database), Rotten Tomatoes, Metacritic and Box Office Mojo are American websites specialized in the motion picture industry (information on movies, critical reviews, web user reviews). 
These results can be considered proof of a convergence of tastes, between specialists and ordinary consumers, in the American motion picture sector, as theorized by the different approaches cited above (disappearance of boundaries, omnivorousness, eclecticism, postmodern tolerance). It is impossible to know whether this convergence is preceded by a period of divergence, or if tastes in this area have always been convergent. The status of "mass art" (Carroll, 1997) that is specific to movies, easily accessed by all with no prerequisite knowledge, seems to plead in favor of the second hypothesis. In fact, the slightest formalization of evaluation standards for mass works by specialists, compared to other art forms that require more knowledge (classical music, fine arts), encourages competition between professional experts and ordinary consumers in constructing the meaning of works and a scale of values (Bielby and Bielby, 2004), thus contributing to the convergence between specialist judgments and those of ordinary consumers.

We can also analyze the results of Holbrook and Plucker in the light of their methodological choices. Except for the initial study conducted by Holbrook (1999), the authors always rely on data collected on movie websites as a measure of specialist and/or ordinary consumer tastes. Does the aggregate judgment of heterogeneous media reviewers, which are known to depend on both audiences and advertisers, represent a valid operationalization of the value judgment of the field's specialists i.e. the small circle of experts that sets its aesthetic standards? Are the opinions of students, collected through a poll, or the judgment of web users on specialized sites, an accurate reflection of the views of ordinary consumers, who may not have the same level of education or involvement as students, or the "day-to-day expertise" usually associated with active web users (Flichy, 2010)? 
This study proposes re-examining the question of divergence or convergence of tastes in a French context, while updating measurement options for specialist and ordinary consumer judgments.

\section{MEASURING CONVERGENCE OR DIVERGENCE OF TASTES IN A FRENCH CONTEXT}

Research question

The aim of this article is to examine the validity, in the context of the French motion picture industry, of two competing theories concerning the relationship between specialist tastes and those of ordinary moviegoers. Divergence theories argue, in the context of a cultural hierarchy that is still prevalent, specialist judgments and those of ordinary consumers exist independently from each other or are even diametrically opposed. Convergence theories anticipate, on the contrary, a closer relationship between the specialist's criteria and those of ordinary consumers: the masses would have, in part, "good taste". A positive correlation (respectively null or negative) between the aggregate tastes of specialists and ordinary consumers would be incompatible (and respectively compatible) with divergence theories.

The results obtained in the United States, compliant with contemporary convergence theories, could lead us to put forward a similar hypothesis for France i.e. there is a positive correlation between the specialist's and ordinary consumer's tastes. However, two factors raise doubts. The first concerns the specific character of the French motion picture industry, with its more assertive artistic status and a more developed autonomous pole than in the United States, along with a more important institutionalization of the criteria of "good taste", which is quite distinct from the taste of the public at large. The second factor concerns the specific means of measuring aggregate tastes observed on specialized websites and which could have constructed, in previous research, the convergence observed.

Measuring taste

\footnotetext{
${ }^{5}$ Criteria widely published by public regulatory and funding organizations (CNC), schools (school field trips, Baccalaureate in Cinema) and universities, operators (the dichotomy between the "art house" and commercial circuits), prestigious and highly mediatized events like the Cannes Film Festival.
} 
We consider, along with Holbrook (1999) that, generally speaking, taste is a concept similar to preference. We adopt Zenatti's definition of taste (1994, p 177), which explains that this preference is based on a value judgment or a pleasure judgment, or both: [taste for a given work is] "the assessment of its qualities, its value on the one hand, and awareness that a given work pleases or displeases us on the other. [taste] is observed in preferences and expressed by judgments that mainly concern either the value granted to the work or personal feelings of enjoyment" (Zenatti, 1994, p 177) ${ }^{6}$. This definition allows us to specify the status of judgment in relation to taste. Judgment is a discursive (verbal or written) manifestation of taste. Therefore, in this study we consider the evaluation of a work (in terms of value and/or enjoyment) contributes to a preference (or not) for it, which is expressed through a (more or less favorable) judgment. Combined judgments define what we refer to here as a "universe of taste". When this is made available to the public on a market, it constitutes what Karpik (2007) calls a "judgment device".

\section{Measuring specialist tastes}

In the work of Holbrook and Plucker, specialist judgments are those of critics. While Holbrook (1999; 2005) collects critical reviews from 6 magazines dedicated to film written by “essayists”, Holbrook and Addis (2007), Plucker, Holden and Neustadter (2008), as well as Plucker et al. (2009) mainly use aggregate evaluations by a multitude of media critics posted on specialized websites (Rotten Tomatoes, Metacritic). In this study we complete this perspective with an alternative measure that is closer to the concept of the specialist's "value judgment". We propose two distinct measures of specialist tastes:

- First, we use tastes expressed by professional media critics, collected on the web. Media critics can be considered "passers" who apply aesthetic systems constructed by specialists in aesthetics and art historians in reviews written for the general public (Becker, 1982). In France, the main website dedicated to motion pictures, allocine.fr, offers reviews of all movies from twenty or so newspapers, magazines or websites ${ }^{8}$, ranked on a scale of 0 to 4 stars. For each movie, we calculate an index based on the

\footnotetext{
${ }^{6}$ Author's translation

${ }^{7}$ According to Karpik (2007, 68-69) "Judgment devices serve as a reference for individual and collective initiative. (...) (They) are designed by multiple players: producers, sellers, market professionals, mass media, public authorities. They are increasingly numerous, increasingly diversified and visible in the public arena. They form five broad categories: networks, appellations, cicerones, rankings and confluences." (Author's translation)

${ }^{8}$ See the list of media in Appendix 1.
} 
number of critics awarding 3 to 4 stars to a movie compared to the total number of reviews. This percentage of "satisfied" critics offers the advantage, compared to a simple average of "stars", of a normal statistical distribution (Basuroy, Chatterjee and Ravid, 2003). Holbrook (1999), following, along with others, Bourdieu's lead (1979), warns of the dangers of using media critics to assess specialist tastes as the commercial goals of their employers encourage them to anticipate and adapt to audience tastes. Moreover, we can postulate that this aggregate judgment reflects the opinion of legitimate critics, offering a formal analysis of the art of cinema (such as those writing for the Cahiers du Cinema) as well the evaluations of ordinary journalists acting as "consumer guides" and offering brief reviews without claiming to be experts ${ }^{9}$ (e.g. Elle magazine, the free newspaper 20 Minutes).

- To avoid the limitations of a measure of specialist tastes based exclusively on media critics, we also included an independent and institutional measurement by professional experts. This is the "art et essai" label awarded to certain films. This recommendation is awarded by a college of 100 recognized experts in the field (critics, artists, intellectuals, industry professionals and representatives of certain CNC commissions). Managed by the AFCAE (Association Française des Cinémas Art et Essai) and mandated by the CNC (Centre National de la Cinématographie), this "invisible academy" (Urfalino, 1989) meets twice a month to vote on the new movies released (or about to be released), recommending certain of them for the "art house" theatre circuit due to their quality, interest or originality. Less influenced by audience tastes than media critics, the type of assessment required of college members (which is not made public, except among professionals) has the advantage of being closer to a pure value judgment, the question asked of specialists being whether the qualities of the movie qualify it as a "work" rather than a standard entertainment product. In the end, more than half of these movies are recommended for "art house" theatres ${ }^{10}$.

Measuring the tastes of ordinary moviegoers

\footnotetext{
${ }^{9}$ On the differences in professional profiles and levels of expertise between critics and cultural journalists, see, in particular, Brown (1978), Shrum (1996) and Harries and Walh-Jorgensen (2007).

10 "More than half of all new movies receive the Art et Essai recommendation. Over the last ten years, this share has varied between $45 \%$ (in 1999) and 61.7\% (in 2004). In 2005 it was 60\%." (Source: L'exploitation des films recommandés art et essai, CNC, October 2006, page 32; author's translation). This figure seems high, but it is important to bear in mind that these movies represent, globally, a third of all new releases in 2005.
} 
Holbrook (2005) and Holbrook and Addis (2007) measure popular taste according to the number of web users posting evaluations of a movie on the Internet Movie Database (Imdb.com). Plucker, Holden and Neustadter (2008), on the other hand, refer to the evaluations posted by web users on specialized sites: Imdb, Rotten Tomatoes and Box Office Mojo. However, Holbrook (1999) measures popular tastes using results from a satisfaction survey conducted by the cable television channel HBO with a sample of subscribers after broadcasting each movie. Plucker et al. (2009) also use a satisfaction survey, conducted with 169 students. Operationalizations of these previous studies therefore remain very heterogeneous. In our study we use these two levels of measurement, with the tastes of web users on the one hand and satisfaction measured through an audience survey on the other:

- Using data from the website allocine.fr, we first recorded the level of appreciation among web users, ranked the same way as by critics i.e. on a scale from 0 to 4 stars. For each movie, the number of web users awarding 3 to 4 stars is compared to the total number of user reviews (once again, this percentage is better than an average in terms of the distribution's normality). As Plucker et al. suggest (2009) it is important to bear in mind that web users posting reviews on specialized websites and publicly expressing their views are perhaps not ordinary moviegoers, but rather "cyber movie buffs" (Ethis, 2005) or "amateurs" as understood by Flichy (2010), i.e. expert consumers (in the traditional sense of the term: "knowledgeable through experience") and who use the Internet to share their opinions with a vast community of peers.

- In order to estimate ordinary audience tastes more precisely, we also recorded judgments expressed by theatre audiences during the first days after a movie's release. These surveys are conducted by an organization that is recognized by industry professionals (the Observatoire de la Satisfaction) and the results are published weekly in the French professional magazine Ecran Total. This polling firm records the opinions of 100 to 200 moviegoers each week concerning major releases (3 to 5 movies, usually the most popular ones), questioned at the exits of several multiplex theatres in Paris and its suburbs. These opinions are transformed into a level of satisfaction for a movie ranging from 0 to 4 . We calculate an index based on the number of people who are "satisfied" (level 3) and "very satisfied" (level 4) with a movie compared to the total number of moviegoers questioned. This measurement limits our sample to 3 to 5 of the most "popular" movies according to the Observatoire de la Satisfaction (among the 12 to 15 new releases each week). However, compared to web user reviews, this guarantees a priori greater heterogeneity among the 
respondents and is closer to a pleasure judgment (a first impression directly after the screening) than the web user's judgment, which is formulated later, often written and supported by arguments and bolstered by other evaluations ${ }^{11}$.

Movie database

The four measurements of taste were collected from a sample of 622 popular movies released in French theatres between May $1^{\text {st }} 2005$ and December $31^{\text {st }} 2009$. The table below presents their characteristics.

Table 2 -Measures of judgment

\begin{tabular}{|l|c|c|c|}
\hline & N & Average & $\begin{array}{c}\text { Standard } \\
\text { deviation }\end{array}$ \\
\hline Specialist judgment & \multicolumn{2}{|l|}{} \\
\hline $\begin{array}{l}\text { Institutional specialists } \\
\text { (art et essai recommendation: yes/no) }\end{array}$ & 622 & 0.275 & 0.446 \\
\hline $\begin{array}{l}\text { Media specialists } \\
\text { (critics: \% of positive evaluations) }\end{array}$ & 622 & 38.0 & 27.5 \\
\hline Ordinary consumer judgment & 622 & 31.5 & 14.8 \\
\hline $\begin{array}{l}\text { Web users } \\
\text { (\% of positive evaluations) }\end{array}$ & 622 & 75.4 & 14.0 \\
\hline $\begin{array}{l}\text { Theatre audiences } \\
\text { (\% of positive evaluations) }\end{array}$ & \multicolumn{2}{|l}{} \\
\hline
\end{tabular}

A descriptive statistical analysis reveals two important characteristics of the movie sample. On the one hand, the sample includes $27.5 \%$ of "recommended art et essai" movies (compared to a little more than half of all new movies). This lesser percentage results from limiting the sample to "major releases" of the week. Also, the movies in the sample consecrated by institutional specialists are not highly confidential or specialized works, but "exceptional" movies distinguished from others by certain "artistic" characteristics ${ }^{12}$. On the other hand, on the same scale (cf. Measuring tastes) the standard deviation of the measure of media specialist judgment is twice that for web users. This confirms the broad heterogeneity

\footnotetext{
${ }^{11}$ Even if these are limited to other user reviews or the opinions of critics displayed on the same page of the website allocine.fr.

${ }^{12}$ We can find, for example, films with successful careers in France like Woody Allen's "Vicky Cristina Barcelona”, Riad Sattouf's “The French Kissers”, Quentin Tarantino's “Inglorious bastards”, Cedric Klapisch's "The Russian Dolls" or Clint Eastwood's "Gran Torino".
} 
of the media critics group, reflecting varying levels of expertise as well as, undoubtedly, a desire to adapt to the different tastes of their respective audiences. The fact that web users in the sample are harsher on average than critics (31\% vs. $38 \%$ of positive reviews) supports this hypothesis.

THE STRUCTURE OF CINEMATOGRAPHIC TASTES IN FRANCE: RESULTS AND DISCUSSION

From divergence to a constructed form of converging tastes

If we consider, like Holbrook or Plucker, the judgment of media critics as a standard of legitimate taste in the field, the results presented in Table 3 reveal a partial convergence of tastes. Movie audiences $(r=0.194)$ as well as web users $(r=0.494)$ display at least some "good taste". However, when we select the judgment of institutional specialists as our standard of "good taste", we can observe two distinct phenomena:

- Ordinary consumer tastes are independent from those of specialists $(r=0.004$; divergence)

- On the contrary, web users display partial "good taste" ( $r=0.300$; convergence)

Table 3 - Correlations matrix between measures of judgment

\begin{tabular}{|c|c|c|c|c|}
\hline Correlations matrix & $\begin{array}{c}\text { Institutional } \\
\text { specialist } \\
\text { judgment } \\
\text { (Art et Essai) }\end{array}$ & $\begin{array}{c}\text { Media specialist } \\
\text { judgment } \\
\text { (critics) }\end{array}$ & $\begin{array}{c}\text { Web user } \\
\text { judgment }\end{array}$ & $\begin{array}{c}\text { Theatre audience } \\
\text { judgment (exit } \\
\text { interviews) }\end{array}$ \\
\hline $\begin{array}{c}\text { Institutional specialist } \\
\text { judgment } \\
\text { (Art et Essai) }\end{array}$ & 1 & $0.593 * *$ & $0.300 * *$ & 0.004 \\
\hline $\begin{array}{c}\text { Media specialist } \\
\text { judgment } \\
\text { (critics) }\end{array}$ & 1 & $0.494 * *$ & $0.194 * *$ \\
\hline $\begin{array}{c}\text { Web user judgment } \\
\text { (Ad }\end{array}$ & & 1 & $0.399 * *$ \\
\hline
\end{tabular}

Thus, when we mobilize new and more valid measures of the specialist's value judgment and the ordinary moviegoer's pleasure judgment, the hypothesis of diverging tastes - in this case independent tastes - seems to be confirmed ( $\mathrm{r}=0.004$; ns). By evaluating the tastes of the general public based on those of web users and/or measuring specialist judgments based on 
those of media critics, the phenomena of "little taste" takes shape, which was theorized by Holbrook and supposed to reflect the partial convergence of tastes in contemporary society.

Table 3 allows us to observe, as well, the expression of a universe of intermediate or hybrid tastes between those of institutional specialists and ordinary spectators. The tastes of web users is situated, in fact, "somewhere in the middle" between specialist judgments (institutional or media with correlations of respectively $r=0.300$ and $r=0.494$ ) and theatre audiences $(\mathrm{r}=0.399)$. As for the aggregate judgment of media critics, it seems as close to that of web users $(r=0.494)$ as that of institutional specialists $(r=0.593)$.

These results appear robust, whether we consider movies that benefitted from limited, average or wide releases (in numbers of copies during the first week of release) or if we examine them according to their year of release (2005, 2006, 2007, 2008 or 2009). The correlation between specialist and ordinary moviegoer judgments is never significantly greater than zero. The intermediate position of web user and media critic judgments is also confirmed ${ }^{13}$.

\section{Discussion}

These results underline a divergence in tastes between specialists and ordinary moviegoers where previous American studies pointed to a convergence. The tastes of French movie specialists and audiences have a priori nothing in common. It is important to note that the correlation observed here is null and not negative. This result means that what is appreciated by ordinary moviegoers is not rejected by specialists and vice versa. The divergence observed concerns independent $(\mathrm{r}=0)$ and not opposite tastes $(\mathrm{r}<0)$. In particular, there seems to be no distaste or voluntary search for social distinction on the part of an elite group with contempt for "popular" preferences. Instead we can observe two universes of taste with apparently unrelated evaluation criteria. In a period characterized by a mixture of erudite and popular cultures, this divergence attests to the persistent use of distinct evaluation criteria. We can postulate that emotion (pleasure judgment) remains a central criterion for ordinary moviegoers (as is the case for "mass arts" in general; Carroll, 1997), whereas the formal originality of the work remains the standard for specialist judgments (value judgment).

\footnotetext{
${ }^{13}$ Only two results differ. For the year 2005 (from May to December) we can observe a negative correlation (divergence in the sense of contradiction) between institutional specialists and theatre audiences (the absence in the database of movies released at the beginning of the year could influence this result). For the year 2009 the correlation between web user tastes and ordinary moviegoers is null.
} 
This result can be interpreted as the symbolic domination of the consumer by a conservative elite defending an inaccessible criteriology. Conversely, along the lines of Cultural Studies, we can also see in these disconnected tastes the portrait of ordinary consumers who are not incapable of accessing legitimate works, but are indifferent to the canons of "good taste" imposed from on high (Fleury, 2006). While "good taste", more or less faithfully transmitted by institutions in the field (schools, universities, specialized press, dictionaries, encyclopedias, film festivals...) does not influence the preferences of ordinary consumers, we can postulate that the authoritative judgment of specialists is simply not sought after or recognized by the general public. The Internet undoubtedly plays a role in this decoupling by facilitating access to an extremely diversified cultural offer and a wealth of information. The network allows everyone to "tinker" with his/her own criteria and preferences, independently from any legitimate discourse. The result is that ordinary moviegoers evaluate movies in an active way, but according to an alternative value system that totally escapes institutional "good taste" (see the analysis of Bielby and Bielby, 2004, in the case of soap operas).

The positive correlations observed in Table 3, in keeping with the hypothesis of "little taste" put forward by Holbrook or Plucker, suggest that the convergence observed by these authors is constructed by their measurement options:

- Regarding specialists, the mobilization of the aggregate judgment of critics (instead of institutional specialists) always tends to produce positive correlations with audience tastes (whatever the operationalization), supporting the hypothesis that the media system encourages the critic to adapt his judgments, in part, to his audience ${ }^{14}$. Moreover, the strong standard deviation of the measure of critical reviews posted on the web suggests that media specialists make up an artificial aggregate of legitimate critics and ordinary journalists whose heterogeneity leads us to put their "specialist" status into perspective, as understood in the sociology of art.

- Regarding ordinary moviegoers, we can observe that the judgments of web users are systematically closer to those of specialists (whether institutional or media critics) than to those of theatre audiences. The self-selection of web users who decide to post an evaluation, and sometimes an opinion, on a specialized site probably leads to the creation of a sample consisting in a large number of "self-proclaimed novices"

\footnotetext{
${ }^{14}$ For commercial reasons, but also due to the homology between critics and their readers, as explained notably by Bourdieu (1977).
} 
(Plucker et al., 2009), “cyber-cinephiles" (Ethis, 2005) or "amateurs" (Flichy, 2010), rather than ordinary consumers that we can find exiting movie theatres. Somewhere in between the "scholar" and the novice, we can observe a new category of pro-am consumer (professional-amateur), whose knowledge, acquired and broadcast via the Internet, allows him/her to challenge the opinion of legitimate experts on their own turf.

Therefore, the mobilization of these universes of hybrid tastes, constructed and made available via the Internet to both the general public and professionals, suggests an artificial form of convergence, already recognized in previous research, that masks the persistence of a clearly defined separation between specialist tastes and those of the public at large (divergence). We therefore put forward the hypothesis that the convergence of tastes observed in several past studies is not due to the blurring of traditional boundaries between specialist judgments and those of ordinary consumers, but rather to a digital construction of hybrid tastes whose properties situate them in an intermediate position between the tastes of "authentic" specialists and novices. These universes of taste occupy a symbolic space left vacant between the specialist and the novice, proposing an alternative mediation tool whose impact on the market has already been highlighted (Author, 2007).

There remains, among previous American studies, Holbrook's initial research (1999), before the "all Internet" age, based on a poll of television viewers (for the general public's taste) and an index based on six critical works (for the specialist's taste) and which nevertheless concludes there is a partial convergence of tastes (correlation of $r=0.25$ ). This positive correlation cannot be attributed to the biases inherent in measures based on the Internet. We can propose several explanations as to why this result differs from ours. First, HBO subscribers $^{15}$, who were questioned for the survey, would be more avid movie buffs and therefore have tastes closer to those of critics than French audiences questioned at theatres by the Observatoire de la Satisfaction. Secondly, critics who wrote the guides Holbrook used in his study to measure specialist tastes would represent "popular" rather than cinephile trends among critics. Finally, the status of motions pictures as an "art form" would be less

\footnotetext{
${ }^{15} \mathrm{HBO}$ is a premium American cable television network that bases its position on quality and the production of innovative and ambitious programs (series such as The Sopranos, Six Feet Under, True Blood and feature films like American Splendor, Elephant, etc).
} 
pronounced in the United States (dominated by a heteronomous commercial pole than in France, which would diminish the distance between specialists and ordinary consumers.

\section{IMPLICATIONS FOR RESEARCH AND PLAYERS IN THE FIELD}

\section{Theoretical contributions}

This study suggests, first of all, that specialist tastes and those of the general public in terms of motion pictures diverge in that they have no common basis. The specialist's value judgment does not converge with the public's pleasure judgment. This result offers no empirical validity to theories anticipating a convergence of erudite and popular aesthetics, the omnivorousness of cultural elites or even the eclectic dimension of artistic tastes in contemporary society.

We observe a divergence in tastes along with a constructed form of convergence based on universes of hybrid tastes published on the Internet, by users and media critics. The mobilization of either of these two universes, which borrow elements from erudite aesthetics and popular preferences, tends therefore to confirm the hypothesis of convergence. In our opinion, the results of previous American research, observing "little taste" or rather "good taste" among the general public, is due to this construction. Our results do not contradict the conclusions of Holbrook or Plucker, but place them in a broader theoretical perspective, one in which there are plural judgment systems between two disconnected extremes that constitute the specialist's value judgment (legitimate or "good taste") and the ordinary consumer's pleasure judgment (popular taste).

The various universes of tastes constructed via digital technology therefore bridge the gap between specialists and the general public, making the voice of the former inaudible and useless for the latter. In doing so, the market regulates the issue of divergence between the preferences of traditional opinion leaders (i.e. specialists) and those of the general public. The construction and broadcasting of universes of hybrid tastes create a partial convergence that is useful for ordinary moviegoers and give the motion picture market new and effective judgment devices (Karpik, 2007).

Methodological contributions 
Completing previous measures of taste in motion pictures, our results underline the constructed nature of the categories labeled "good taste" and "popular taste". Empirical results vary significantly, according to the type of judgment used to operationalize specialist or ordinary audience tastes. These plead in favor of the "non-taste" of the general public (no correlation between the judgment of institutional specialists and theatre audiences), its "little taste" (positive correlation from 0.2 to 0.3 between institutional specialists and web users or media specialists and theatre audiences), or even its "rather good taste" (correlation of 0.5 between media specialists and web users). Each measure results in the arbitrary construction of a judgment device based on a collective category of actors with specific and mostly uncertain social properties. Up until now, most studies of taste or creativity have opted, for obvious practical reasons, for a measure of specialist judgment based on the media and a measure of audience tastes based on those of web users. By mobilizing universes of taste with certain technical-cultural properties that render them more closely correlated than others, these research choices have created the phenomenon of a partial convergence of tastes.

Our conclusions tend, therefore, to call into question the idea that the judgments of critics or users posted on specialist websites serve as valid proxies for evaluating specialists in the field (legitimate taste) or ordinary users (popular taste). These new web-based measures should rather incite us to redefine the traditional categories of specialist and ordinary consumer, while underlining the construction of hybrid categories, in between the traditional definition of the erudite and the popular. Thus, while web users are collectively "professional amateurs" (Flichy's pro-am, 2010), or in our terms "specialized amateurs", media critics could also be dubbed "amateur specialists".

Implications for consumers and managers in the motion picture sector

The independence of specialist and audience tastes suggests the futility of references to "legitimate taste" for the ordinary consumer. This is why the construction of hybrid tastes (like those of web users or media critics) helps partially solve the problem of the "missing prescription" (or an ineffective one) by proposing useful intermediate reference points for consumers in terms of decision-making (reduction of perceived risk) or self-assessment. Therefore, the general public can refer to the tastes expressed by web users (an audience of similar social status that is more knowledgeable about movies, but not professional or 
commercial), which it shares in part $(r=0.399)$. More avid movie buffs (like web users) can find a closer indication of value in the aggregate judgment of the media $(r=0.494)$ than in the specialist's value judgment $(r=0.300)$. The results of this study also encourage the distributor of formally challenging movies, concerned with broadening his/her audience beyond a circle of connoisseurs who are closer to specialists, to use the judgments of web users as a tool to attract the most involved fringe of the general public. The aggregate judgment of the media could constitute a relevant instrument for convincing undecided cinephiles. Conversely, for distributors of commercial movies, it is better to refer to the judgment of web users than that of the media to attract the general public.

Since the motion picture market demands increasingly numerous judgment devices (Flichy, 2010; Karpik, 2007), another proposal consists in gathering within the same information tool the range of publicly expressed tastes, which are often scattered or difficult to find (besides the judgments mobilized in this study we can cite distributor or operator labels ${ }^{16}$, award nominations and festival prizes, etc.) For consumers, multiple judgments for the same film could certainly make processing information or decisions more complex. However, making available a wide range of hybrid tastes, between the "legitimate" and the "popular", could potentially allow each actor on the market, having identified similarities in judgment between these universes, to more effectively reduce the risks inherent in his/her choices. In the end, the challenge for actors on the market would be to construct, formalize and propose a plurality of recommendations to the general public based on the diversity of tastes expressed regarding movies i.e. contributing to a larger offer on the market of movie judgment devices. Finding the best recommendation tool (i.e. the most relevant ad hoc judgment) would then become, for the consumer as well as the distributor, a major marketing challenge, made even more difficult in the Internet age.

Implications for cultural policies

The first result of this research, i.e. the divergence of tastes between specialists and ordinary consumers, refers to two main theoretical perspectives cited in our review of the literature. On the one hand, according to the Frankfurt School, cultural industries use mass influence strategies. The ordinary spectator is passive and expects productions with standardized

\footnotetext{
${ }^{16}$ For example, the movie theatre operator UGC awards "UGC spectator's choice", "UGC discovery" "UGC M" or “Tomorrow's director's" labels (http://www.ugc.fr/typepage.do?alias=services-ugc).
} 
aesthetics that are easily accessible and of little intrinsic quality. While these consumers are cultural dopes, incapable of recognizing an authentic work of art, it goes without saying that the market cannot ensure the function of consecrating talent alone. This is where public authorities must intervene:

- regarding the offer, on the one hand, by supporting, promoting or distributing artistic works whose quality is recognized by specialists in the field. A recurring theme in cultural economics, the guardianship of cultural products by the State therefore consists in imposing a variety of productions and tastes (Benhamou and Moreau, 2007).

- regarding demand, on the other hand, with the aim of educating and guiding behaviors towards the consumption of legitimate works, by emphasizing education and training and cultivating the tastes of citizen-consumers. In this area, a cultural policy aimed at attracting audiences to movies consecrated by specialists could make use of the intermediate tastes of web users and/or the media. It would be innovative, for example, to use a sort of public seal of approval (Ministry of Culture and/or CNC) to lend credibility to various quality label initiatives (media labels, web user-movie enthusiast labels, or other intermediate universes) in order to ensure the construction of judgment devices is not only left in private hands (like the mention "UGC spectator's choice" or various websites, whose independence can be called into question). Highlighting these "labels" could serve promotional purposes (via their instrumentalization in advertising, for example) guiding the moviegoer and inviting him/her to make more daring choices. Therefore, regarding managerial implications, these labels attributed by various sources would contribute to stimulating demand for more varied or bold works and cultivate tastes in a gradual way in order to form a more refined judgment of value, beyond mere agreeableness.

On the other hand, according to critical sociology, standards of excellence would be constructed intentionally by specialists in order to maintain a distance from the masses of consumers (Bourdieu, 1977). The social system would be based on a normative construction of "good taste" and on the symbolic domination over the general public by a conservative elite defending an inaccessible criteriology, disconnected from the feelings of ordinary audiences. From this perspective, a bold public policy would be required to denounce the rigidity of this system of distinction and social domination. Corrective actions could be proposed to introduce diversity, for example, in the inner circles of the CNC and promoting 
access of non-specialists, whether from a different cultural field (writers, architects, dancers...) or with a different habitus (social, cultural, geographic diversity, etc).

\section{LIMITATIONS AND AVENUES FOR FUTURE RESEARCH}

The limitations of this study lie in the measures selected for specialist and ordinary consumer tastes and which lead us to conclude they diverge. Could other measures have lead to the opposite hypothesis? Regarding specialist tastes, it would have been possible, for example, to use tastes expressed by the most legitimate fringe of motion picture critics (academics, institutions including the Cahiers du Cinéma or Positif...). With regard to the "art et essai" recommendation, this choice has two drawbacks. On the one hand, it has limited the group of specialists to just a few voices among a unique category of gatekeepers (critics), thus excluding other professional experts present in the AFCAE college and ignoring the collective dimension in the construction of "good taste". On the other hand, this choice has restricted the panel of "consecrated" films to a small number of confidential art house movies, which, in fact, the value judgment behind the "art et essai" recommendation seeks to avoid by including a large number of films for a broad audience. Furthermore, the measurement of ordinary consumer taste based on a poll conducted by the Observatoire de la Satisfaction is limited as well because it concerns only early consumers (audiences questioned during the first days after the movie's release), could possibly include web users among the persons questioned and only focuses on "major releases", while neglecting more confidential works (the study concerns 3 to 5 releases a week that are considered the most "important", i.e. the most popular ones). However, we can hypothesize that a measurement of ordinary tastes conducted with subsequent audiences of more marginal works would only amplify the divergence observed between specialist and ordinary consumer judgments. Another limitation concerns the interpretation of the null correlation between specialist and ordinary consumer tastes. We hypothesized that this supported the theory of divergence. Another possible interpretation of this missing link could be that the universe of popular taste consists in erudite and novice poles. The positive correlation between specialist tastes and the erudite fringe of the general public and the negative correlation between specialist tastes and the popular fringe of the general public would therefore result in a null correlation.

A first possibility for future research would be to abandon the aggregate level of analysis in favor of an individual perspective. This would mean taking "popular taste" seriously and 
studying its fundamentals. It is indeed important, if we really want to understand how to address the ordinary consumer who does not speak the same language as the specialist, to analyze the value and justification systems underlying his judgment in greater depth. Beyond the originality and novelty prized by art specialists since the $19^{\text {th }}$ century, some authors point to alternative criteria such as technical quality, edification, emotion, consistency (Jullier, 2000), moral, sensitivity, economic rationale, (feelings of) justice (Heinich, 2001), or even social acceptability (Woodward and Emmison, 2001). We could also study how recent upheavals in movie consumption (cyber-cinephilia, home cinema, unlimited theatre passes, illegal downloads, the multiplication of screens) tend to accompany the emergence of new and multiple ways for audiences to appreciate movies.

A second topic for future research would consist in exploring the correlations between the distributor's marketing efforts and judgments expressed in different universes, particularly among the general public. Traditional critics of the cultural industry denounce the passivity of consumers who allow the forces of mass marketing to shape their tastes (Gans, 1999). From this critical perspective, several fundamental questions can be raised. Do distributors tend to promote films they believe are likely to please the general public or, on the contrary, do they promote mediocre films in order to attract large audiences during their opening weeks, before word-of-mouth can affect box office figures? Do market actors (audiences, web users, media, etc.) really appreciate the most heavily promoted movies i.e. those announced as "must see" works by the studios? To what extent do movies with little or no positive feedback become box office successes thanks to mass marketing? To what extent, as well, do the most highly appreciated movies (which are not necessarily the most viewed) become successes on secondary markets, after their run in theatres (DVD, VOD, television...)?

A final topic for future research would consist in questioning the existence of a divergence between specialist and ordinary consumer tastes in other cultural fields in France. We could indeed put forward the hypothesis that the observation of a divergence or convergence of tastes depends on the institutional, cultural and industrial evolution of each field (visual arts, theatre, music, etc). It would also be interesting to identify, in all their diversity, the different judgment devices available in the public sphere in each field, how they are constructed, their relative proximity with specialist or novice tastes and their instrumentalization by different actors. More generally speaking, all sectors of experiential products characterized by the existence of specialist and novice profiles and an institutionalized process of constructing 
"good taste" could serve as the object of a similar analysis (wine, gastronomy, fashion, design, etc.). Research on the "taste of others", on the market of evaluations and judgments, could become - or is already becoming - a systematic approach among ordinary consumers of experiential products. Indeed, as Karpik points out $(2007,80)$, “competition between products is increasingly replaced by competition between judgment devices"17.

${ }^{17}$ Author's translation 


\section{APPENDIX 1}

List of media used by allocine.fr over the period studied to construct critics' judgments.

Non-specialized daily newspapers

Le Monde, La Croix, Le Figaro, 20 Minutes, Le Parisien, Métro, L'Humanité, Libération, Ouest France, Les Échos

\section{Non-specialized weekly newspapers}

Le Point, L'Express, Le Nouvel Observateur, L'Express, Elle, Paris Match, Charlie Hebdo, Marianne, Le Journal du Dimanche,

$\underline{\text { Specialized weekly and monthly magazines (culture, motion pictures, television) }}$

Les Cahiers du Cinéma, Ciné Live, Les Inrockuptibles, Télérama, Studio Magazine, Positif, Première, Studio, L'Écran Fantastique, Brazil, Dvdrama, Filmsactu, Mad movies, Rolling Stone, Score, Zurban, Télé 7 Jours, le Figaroscope, TéléCinéObs

$\underline{\text { Specialized websites (culture, motion pictures) }}$

MCinéma.com, chronic'art.com, avoir-alire.com, fluctuat.net, cinopsis.com, critikat.com 